


\section{Consecuencias cognitivas de la intervención editorial en la poesía mexicana contemporánea}

\section{Cognitive consequences of editorial intervention in contemporary Mexican poetry}

Alejandro Higashi Díaz Universidad Autónoma Metropolitana - Iztapalapa

Resumen

En este trabajo, me propongo mostrar los componentes principales de distintos tipos de intervención editorial en algunos libros de poesía recientes y sus consecuencias, desde la perspectiva de la psicología cognitiva, en el plano de la percepción y atención. A través de varios ejemplos, exploro las distintas formas en que estímulos atencionales agregados durante el proceso editorial favorecen o inhiben los contenidos transmitidos por los textos líricos mismos.

Palabras clave: intervención editorial, filología material, estímulos atencionales, orientación preatencional, poesía mexicana contemporánea. 
Abstract

In this paper, I propose to demonstrate the principal components of distinct types of editorial intervention in some recent books of poetry and of their consequences, from the perspective of cognitive psychology, in the area of perception and attention. Through various examples, I explore the different forms in which attentional stimuli added during the editorial process favors or inhibits the content transmitted by the lyrical texts themselves.

Keywords: Editorial intervention, Material philology, Attentional stimuli, Pre-attentional orientation, Contemporary Mexican poetry.

\section{La intervención editorial como otra de las Bellas Artes}

$\mathrm{U}$

Tn día, cuando escribamos la historia colectiva de la literatura mexicana que debemos desde hace al menos dos siglos, aflorará una figura inadvertida hasta ahora dentro del proceso de composición literaria: la del editor. Visto siempre como un intermediario pasivo, la presencia de grandes editores literarios es un rasgo de nuestra modernidad que explica, al menos en parte, que autores como Stieg Larsson o Roberto Bolaño hayan logrado ventas millonarias después de sus respectivos decesos. En un libro reciente, titulado precisamente La mediación editorial, sobre la vida póstuma de lo escrito, Jerónimo Pizarro ha demostrado con lujo de detalles cómo la novela más exitosa y conocida de Macedonio Fernández, Museo de la novela de la Eterna, no toma una forma definitiva hasta su muerte y la mediación editorial de Adolfo de Obieta (2012: 93-144). Esto, sin hablar de géneros hoy muy prestigiosos dentro del canon literario mexicano cuyo origen no fue un manifiesto de grupo ni una poética común, sino un cauce preparado por editores que lograron homogeneizar, bajo una etiqueta común, una 
miscelánea de géneros en la que caben memorias, novelas históricas, novelas políticas, relatos autobiográficos, crónicas literarias y periodísticas, cuentos, etc. Pienso en la novela de la Revolución (apuesta que orienta un libro reciente sobre el tema; vid. Torres de la Rosa, 2015), pero también podría insertarse en esta tipología la novela de la onda o la narconovela. En México, resulta imposible disociar el nacimiento de la novela corta de El Universal Ilustrado y del nombre de su principal animador, Carlos Noriega Hope (vid., por ejemplo, Hadatty Mora, 2014) y Poesía en movimiento, de Arnaldo Orfila Reynal, luego de la publicación de las cartas cruzadas entre el editor de la naciente Siglo XXI y Octavio Paz (2005), donde puede verse quién fue el principal animador del proyecto.

En este trabajo, me referiré nada más a una faceta de esta participación activa del editor: la intervención editorial. Se trata de un concepto que debe entenderse en el mismo sentido en el que hoy nos referimos a una intervención artística o museográfica (el resultado de la apropiación de la obra de un autor por otro mediante prácticas concretas que proponen la subversión del discurso museográfico a través de medios más simples o más complejos, como la saturación en espacios reducidos de las piezas, la incorporación de serigrafías en las paredes del museo o de otros objetos ajenos a nuestra noción de arte, etc.; hay varios ejemplos en Juan Martín Prada, 2001) o a una intervención artística en el espacio público (cuando el espacio público se reconfigura para ofrecer una experiencia artística en un espacio inusitado; el arte callejero sería una de sus formas más comunes, pero pueden verse, a propósito, otros ejemplos en Segura y Simó, 2012). En ambos casos, se trata de poner en crisis la noción de autor (el de la obra intervenida ¿es el que crea o el que interviene?), el significado de la obra (¿la obra de arte es obra de arte en sí o está determinada por el espacio museográfico de percepción?) y el significado, de manera general, del espacio (donde importa más crear situaciones que obras de arte en sí). 
La noción de intervención editorial en literatura resulta menos chocante que en artes plásticas porque estamos muy acostumbrados a ella. El trabajo de quien edita un libro es una intervención profesional, mientras que la intervención de un cuadro famoso en el contexto museográfico puede ser vista como un desacato artístico reprobable, como un acto genuinamente artístico de fuerte compromiso político o como una mera ocurrencia. Una vez asumido que todo aquel profesional que edita realiza algún tipo de intervención editorial, el catálogo de posibilidades puede ser muy amplio: desde minucias como una coma por aquí, una tilde olvidada por allá, hasta trabajos de mayor calado en los que muchas veces el autor del libro puede no participar, como la elección de una tipografía, un tipo de papel o una portada; la mera selección de la obra para una colección y no para otra sugiere ya una intervención editorial. En algunos casos, la intervención puede llegar a cambiar, incluso, el sentido original de la obra; pensemos en una edición crítica repleta de minuciosas notas a pie de página: lo que antes era una obra de entretenimiento (pongamos, por ejemplo, el Quijote) se transforma, en virtud de esta intervención editorial, en un abultado clásico y en un libro de estudio con varios niveles de lectura (texto, introducción, estudios, notas a pie de página, notas de variantes, etc.; no hay que olvidar que en artes plásticas el concepto de intervención también se aplica para una restauración apresurada y que no tiene en cuenta las características originales de la obra). Cuando analizamos la obra poética, a menudo olvidamos que dicha obra se materializa en un soporte realizado por un colectivo de creadores, llamado libro, donde el autor sólo participa de forma parcial, cuando no es mero espectador.

La obra y el libro son objetos distintos y el soporte material está sujeto a reglas de producción muy diferentes a las de la obra poética, aunque sea el soporte material la primera interfaz sensible para quien lee y enfrenta la experiencia de lectura. La diferencia, 
me parece, se ha radicalizado en los últimos años debido, en parte, a diversas veleidades del mercado editorial. En primer lugar, la falta de éxito comercial del libro de poesía; en segundo, el imperioso requisito comercial de ofrecer libros de diseño atractivo que se vendan, incluso si se trata de libros de poesía; en tercer lugar, la inseguridad cada vez más notoria en los mismos poetas respecto al texto poético en sí. Sobre el primer punto no hay mucho qué decir: hace mucho que, al menos en México, los libros de poesía no son éxitos de venta, como puede constatarse en las mesas de novedades y, desde una perspectiva más crítica, en la indispensable edición o coedición con fondos públicos de las editoriales que se arriesgan (y subrayo el tono irónico) a publicar libros de poesía (Era, Aldus, FCE, Fonca, Conaculta, las colecciones universitarias, etc.; se salvan, hasta ahora, Almadía, VersodestierrO y muchas editoriales idealistas y pequeñas que terminan en la quiebra).

Sobre el segundo, quien edita es responsable de vender los libros de la tirada y, para asegurarse de cumplir con su cometido, recurre a valores agregados que hagan atractiva la compra (y, en ocasiones, hasta la lectura). Algunas estrategias pueden resultar muy obvias (colores abigarrados en las portadas, grandes formatos) y otras más, sutiles en extremo. En los últimos años, el Fondo de Cultura Económica ha cambiado la presentación de sus Obras completas: ahora, se trata de volúmenes más manejables gracias a una encuadernación en cartulina y un papel de gramaje más bajo que permiten sostener el libro con menos esfuerzo que en las pesadas ediciones de pasta dura en papel cultural; el libro, en resumen, se lee con más facilidad desde la perspectiva del esfuerzo físico (lo que debe de impactar de algún modo en la experiencia de lectura). VersodestierrO y Almadía son dos editoriales muy diferentes, tanto en listado de autores y propuesta editorial como en esquema de negocios, aunque coinciden en el plano de proponer una estética lúdica para el libro de poesía. La plusvalía del diseño es la única 
defensa que le queda a quien edita ante los embates de los programas de cómputo de autopublicación y el aumento de blogs y sitios gratuitos para la distribución, factores que promueven la ilusión de la autoedición para el no profesional (podríamos llamarlos juegos de simulación editorial). Al convertir al lego en pseudoeditor digital, terminan por devaluar la formación profesional del editor (en el terreno de la fotografía periodística, por ejemplo, el celular oportuno ha liquidado al fotorreportero; en el de la fotografía profesional, el Instagram; en el del retrato, la selfie cuando la cámara se pudo colocar en el mismo lado que la pantalla, etc.). Esta coacción orilla al editor a exhibir más explícitamente su participación.

En tercer lugar, respecto a la importancia de la obra para quienes la crean (y sin pensar en el libro), como ha sugerido Malva Flores en La culpa es por cantar, parecería que los y las poetas actuales padecen una inseguridad emocional ante el número reducido de lectores y lectoras (lo que, en el fondo, no debería sorprender, pues así ha sido desde Baudelaire y Mallarmé, como apunta Flores, 2014: 34-37) y su creciente desplazamiento comercial frente a quienes escriben narrativa (tema del capítulo "La fortuna de la prosa”, Flores, 2014: 91-100). En condiciones poco favorables, la comunidad poética nada contra corriente y encuentra en la vertiginosa simultaneidad de las redes sociales, en el ambiente festivo de los congresos de poesía, en la improvisación de los jams, en la teatralidad del spoken word, etc., una oportunidad para encontrar un público mayor a través de la performance. Por desgracia, todas estas actividades compensatorias parecen alentadas por la desconfianza en la autosuficiencia del texto poético para destacar por sí mismo. El trabajo editorial y la performance poética podrían ser tipos diferentes de intervenciones con un mismo propósito: disimular nuestra inseguridad en la capacidad del poema para despertar interés por sí mismo. 


\section{El libro como interfaz del proceso de lectura y la poética cognitiva}

La intervención editorial tiene una amplia tipología y una historia que no me interesa agotar en estas páginas, pero entre sus hitos más importantes seguro se ubicarían las obras de José Juan Tablada, las de Manuel José Othón o varias obras de Octavio Paz, donde los poetas trabajaron de forma muy cercana con los editores para alcanzar los objetivos propuestos. No pensaron en textos, sino que pensaron en libros directamente. Me interesa, por el contrario, considerar las consecuencias cognitivas de esta intervención, cuyo valor epistemológico me parece poco asimilado en la actualidad. $\mathrm{Si}$ quien escribe el poemario carga con la responsabilidad de las decisiones estéticas, a quien edita le toca iniciar, desde la portada y la contraportada, un diálogo intenso con el lector o lectora, que se continúa en la disposición del texto, el tipo de letra, el tipo de caja, las ilustraciones si las hay, el formato, el tipo de papel, etcétera y, de forma general, la experiencia sensorial de lectura.

Estos factores pueden parecer fortuitos para la teoría literaria tradicional, pero desde la perspectiva de una poética cognitiva y de una filología material representan la primera interfaz de comunicación intuitiva entre quienes escriben y quienes leen poesía. El que lee no llega a la emoción ni a la comprensión por el texto poético en sí mismo, sino por una sensación táctil al manipular el libro, olfativa al acercarlo, visual al percibirlo como unidad desde su portada hasta su contraportada, más otro conjunto rico de asociaciones cognitivas conscientes o inconscientes que pueden establecerse en el proceso. La manipulación del libro como objeto material permite percibir si el poema se ubica al principio o al final de poemario, lo que podría indicar que se trata de una suerte de poética (si al principio) o de una conclusión (si al final) y hacerlo destacar del conjunto. Nadie espera que un manifiesto estético se encuentre en 
las páginas centrales del poemario, porque se trata de una presentación del conjunto. La experiencia sensorial del primer contacto se debe en mucho, adviértase o no, a las decisiones de quien edita, y es innegable que determina en muchos sentidos la interpretación del texto que contiene.

Este conjunto de variables se aprecia mejor desde una plataforma transdisciplinaria como la que provee la poética cognitiva. Al tratarse de una disciplina en desarrollo, estamos muy lejos de contar con un cuerpo homogéneo y consolidado de líneas de investigación. Como puede verse en el panorama general preparado por Peter Stockwell, uno de los primeros ejercicios de sistematización de la disciplina (2002), se trata de un conjunto de principios que coinciden en su interés por los avances del cognitivismo clínico, pero cuyos orígenes se sitúan en la psicología cognitiva, la lingüística cognitiva, la filosofía o la neurobiología misma. Esta base dinámica despliega varias líneas de investigación directamente relacionadas con la poesía, desde los trabajos de Reuven Tsur (2012, 2008 y 2003) sobre la alternancia de patrones y desviaciones de la métrica y el impacto de estos procedimientos en quienes participan del fenómeno poético en los distintos planos de la lectura y la performance, hasta trabajos más recientes enfocados en las estrategias narratológicas y en la formación del sentido (siempre, claro, en relación productiva con enfoques cognitivistas; por ejemplo, Isabel Jaén y Julien Jacques Simon, 2012). Por desgracia, en los últimos años se ha impuesto una marcada preferencia dentro de los estudios de poética cognitiva por textos eminentemente narrativos, por lo que conceptos fundamentales para el estudio de la literatura como los de iconicity, diagrammatic strategies, cognitive mapping o subjectivity (pienso en los trabajos de Christina Ljungberg, del grupo Iconicity de la Universidad de Zurich, 2012, 2009 y 2007) esperan una adaptación al ámbito del análisis del texto lírico. Incluso en obras de divulgación impera el interés por la narra- 
tiva (vid., por ejemplo, Volpi, 2011). Sobre un acercamiento como el que propongo en estas páginas, desde el doble filón de la poética cognitiva y la filología material, sobra decir que no conozco otras incursiones previas y que me alegraría mucho que las hubiera.

Sobre los aspectos directamente relacionados con la percepción, los enfoques también distan mucho de ser homogéneos. Desde la neurobiología, Semir Zeki, solo o en colaboración (Zeki, 2015, 2015a; Cheadle y Zeki, 2014; Ishizu y Zeki, 2014; Shigihara y Zeki, 2013; Zeki y Romaya, 2010 y Zeki y Stutters, 2013), ha identificado las zonas de la corteza visual primaria (V1) y secundarias (V2, V3, V4 y V5) que participan de los diferentes procesos perceptuales a través de una red de enlaces entre sistemas paralelos; así, nociones variables como el color o el tamaño (el color depende de los cambios en la longitud de onda de la luz refleja y el tamaño de un objeto varía de acuerdo con la distancia) son interpretadas por el cerebro para crear datos invariables a través de un proceso de abstracción complejo. La identificación de áreas especializadas en los procesos perceptivos (las formas dinámicas, por ejemplo, se procesan en V3; el análisis cromático en V4 y el análisis del movimiento en V5; V2 parece estar en relación con la memoria visual a largo plazo) apunta naturalmente a procesos complejos que exigen un mayor esfuerzo cognitivo. Pese al interés del paradigma neurobiológico ( $\mathrm{y}$ a la formación de una rama conocida como neuroestética), las aplicaciones prácticas de estos avances en áreas como la creación estética o el amor (Zeki, 2009) no dejan de ser, pese a su enorme valor científico y filosófico, fuertemente especulativas. El mismo problema, llevado al terreno de la psicología cognitiva, produce resultados diferentes, como los que pueden apreciarse en los trabajos compilados por Enric Munar, Jaume Rosselló y Antonio Sánchez-Cabaco (1999); ahí, la percepción se estudia como un fenómeno complejo que va de los estímulos perceptivos y las respuestas perceptivas iniciales del sujeto hasta la formación de 
representaciones mentales inteligibles, con una serie muy rica de procesos intermedios, hasta la constitución de un modelo integral. Ante su incapacidad para procesar toda la información externa de forma simultánea, el sujeto filtra o selecciona (perfila, en la teoría de Langacker) los estímulos más pertinentes de la situación y crea con ello focos o ventanas atencionales (como las define Talmy) sobre el conjunto general de todos los datos de la situación comunicativa, para considerar nada más aquellos fenómenos con mayor relevancia para formalizar un esquema de imagen. Frente a esta noción de la atención como un proceso complejo, la lingüística cognitiva se concentra en las implicaciones lingüísticas de todo el proceso; así, en los estudios de semántica cognitiva (por ejemplo, Paula Cifuentes Férez, 2016), el sistema de distribución de la atención se orienta fundamentalmente hacia el análisis del enunciado lingüístico, donde conceptos como el de ventana atencional aluden a su realización lingüística: en la oración "El niño entró a la habitación, la cruzó y se marchó por la otra puerta”, se atiende a un proceso, pero en "El niño se marchó por la otra puerta" se abre una ventana atencional hacia los resultados del proceso. Aunque los conceptos de atención y percepción resultan fundamentales para las tres disciplinas, cada una los define y utiliza de forma distinta.

La poética cognitiva, por su parte, puede recurrir al instrumental teórico de la neurobiología, la psicología y la lingüística cognitivas, sin entrar en contradicciones con ninguna, para reconstruir el proceso de lectura como un evento complejo formado por la interacción entre el sistema lingüístico (el texto) y el sistema perceptual que se despliega a su alrededor (el soporte del texto). De ahí su enorme valor. Aunque en la actualidad el interés de la poética cognitiva parece centrada exclusivamente en los componentes textuales del poema y las amalgamas conceptuales que pueda formar con las experiencias previas de quienes leen (por ejemplo, Margaret H. Freeman, 2012), no hay que olvidar que el libro en sí 
mismo (incluso como unidad discreta) ofrece una gama constante y dinámica de estímulos complementarios a la lectura de los textos en sí, como espero demostrar en las páginas siguientes.

El libro de poesía, el estímulo perceptivo y el proceso preatencional o el arte de leer con cuidado.

La conexión especial entre la poesía y el soporte que la contiene, menos frecuente en las obras narrativas, no es difícil de explicar. Quien lee poesía naturalmente tiende a fijarse, con mayor interés que en otros géneros, en los componentes formales del discurso, de los cuales el libro mismo sería una extensión más. Desde este perspectiva, tampoco puede considerarse un hecho accidental la frecuente coincidencia entre el libro de poesía y el libro artístico: poesía y artes plásticas persiguen un fin común, incidir sobre un público que puede atender a la forma del mensaje, en ocasiones por encima del mensaje mismo (pienso en los poemas breves, donde resulta más llamativo el espacio en blanco que el propio texto). Como ha señalado, con un propósito distinto, Jean-Marie Schaeffer, el proceso comunicativo, por lo general, se basa en un principio de economía donde muchos de los aspectos formales del texto se hacen a un lado para concentrar la atención en el mensaje:

La dinámica por defecto del acto de comprensión verbal se funda en un principio de economía: se trata de comprender lo más rápidamente posible, gastando la menor cantidad de energía atencional. Esto explica especialmente por qué, en una situación de comunicación normal, nuestra atención no se detiene en la materialidad sonora de la señal, en su ritmo o en sus características estilísticas, y sólo trata a todos estos elementos en la medida en que son indispensables para la comprensión del mensaje (2013: 111). 
La concentración de significados en unos pocos significantes del texto poético explica que las ventanas atencionales tengan que orientarse a otros planos de la lengua como el ritmo, las figuras estilísticas, el uso de los blancos en la página, la tipografía, la topografía en el poemario y ya no exclusivamente al mensaje. Quien lee necesita desplegar una mayor energía atencional porque el discurso poético se desdobla en distintos códigos de significación y todos ellos resultan pertinente para la lectura del texto poético. JeanMarie Schaeffer resume con acierto este proceso complejo:

En cambio, en el marco de la relación estética, como la propia atención, y aquí pues la lectura como acto, es el objetivo de la conducta, ésta ya no obedece al principio de economía, sino que, por el contrario, maximiza la inversión atencional. La poesía manifiesta de un modo muy claro esta transformación en la economía del tratamiento de las informaciones, ya que focaliza la atención en las propiedades que sólo tienen, por fuera de su campo, un vínculo puramente convencional con el "contenido". [...] Para permanecer en la poesía, el hecho de acordar una atención sostenida a la sustancia sonora, a las rimas y los ritmos, se traduce en una prolongación del tratamiento cognitivo que culmina en una sobrecarga atencional (en relación con la situación estándar) (2013: 110-111).

El análisis literario que considere la perspectiva de la lingüística y la psicología cognitivistas puede y debe extenderse a las capas de percepción material que normalmente han prevalecido en el terreno sombrío de lo fortuito, trabajo atribuido a un, en ocasiones, anónimo editor o editora, responsable de orientar la sobrecarga atencional cognitiva entre el texto y el soporte material sobre el que se transmite. 
a) El caso de No todas las islas

Cuando Zazil Alaíde Collins ganó el Premio Estatal de Poesía Ciudad de La Paz 2011 y con ello la publicación del poemario por el Instituto Sudcaliforniano de Cultura, la oportunidad puso el libro en el camino de un editor amigo suyo, Efrén Calleja Macedo, y de un diseñador, compañero de estudios de este último en la Maestría en Diseño y Producción Editorial de la Universidad Autónoma Metropolitana - Xochimilco, Benito López, para realizar entre los tres una edición que rebasara lo que suele ofrecerse en el rubro de la intervención editorial tradicional (la historia ha sido recogida en Calleja Macedo, 2013: 15-20). La transformación fue radical, si se tiene en cuenta que el libro ganador del premio, No todas las islas, era un libro en un formato convencional (poemas breves con disposición colométrica tradicional), lo que difícilmente se ha podido tener en cuenta dentro del cauce de la recepción del libro después de la intervención editorial. Jair Cortés, en una de las pocas reseñas que recibió, obvia el complejo proceso de intervención editorial y coloca el libro en la perspectiva de las vanguardias poéticas, la Tirada de dados de Mallarmé y los caligramas de Apollinaire, lo que le permite afirmar, por ejemplo, que "la aparición de la computadora y la internet han dado un giro inusual a la escritura poética: ahora podemos ser no sólo creadores de una obra, sino editores de la misma, gracias a las múltiples herramientas que nos ofrecen disenar nuestros poemas". En realidad, Zazil Alaíde Collins más bien participó dentro de un proyecto de intervención editorial cuando los poemas ya habían sido escritos en un formato convencional.

Los poemas de No todas las islas no son, para empezar, una extensión de la experiencia creadora unitaria de su autora. El experimento se centra en la búsqueda transdisciplinaria y colectiva (donde participaron la autora, el diseñador y el editor) de una $t i$ pografía poética estratégica a través de la cual los contenidos de los 
textos se continuaran perceptivamente en la disposición del texto en la página, con lo que la experiencia lectora se desarrollaría en un plano más intuitivo (esa fue, al menos, la intención con la que se realizó la intervención editorial). La geografía marina y los temas que trata (en su mayoría, recuerdos que involucran de distintas formas al mar) se transmiten a quien lee desde la misma selección de tintas (tinta azul 640U en distintos porcentajes, al 80\%, 60\%, $40 \%$ y $20 \%$ ); la textura marina se refuerza por medio de la ondulación de los versos y los continuos cambios de tamaño de la fuente (Calleja Macedo, 2013: 55-60). ¿La tipografía extiende la experiencia intuitiva del libro hasta el lector? ¿El uso de tintas azules envuelve a quien lee en la experiencia cognitiva de internarse en un mar poético? Se trata de afirmaciones difíciles de probar, pero también resulta innegable una intencionalidad editorial, expresada en la bitácora del trabajo, como la asociación mecánica que se impone entre los temas marinos y los tonos azules de la tinta (Calleja Macedo, 2013: 57); como la amalgama conceptual o blending entre los temas y el dinamismo del paisaje marino, sugerida por medio de ciertas estrategias: la combinación de diferentes familias tipográficas (2013: 58-60), la identificación de algunas consonancias textuales (los poemas titulados "Día...", de distribución ascendente, pero aleatoria) y su identificación por su diseño a doble página para marcar un ritmo de lectura más pausado y reflexivo (64-65), la construcción de un ritmo visual que sirvió para unir poemas cercanos temáticamente a través de consonancias en el diseño (tipo y tamaño de letra, color de tinta, impresión en página doble) y subrayar las disonancias de algunos otros por medio de una disposición vertical (68-72); la desproporción entre los títulos y los textos, aunque entre ellos se plantea más bien un recorrido solidario y "no un salto tipográfico" (58); algunos bloques de texto en el documento en MSWord se descompusieron con distintos propósitos en varios bloques de dimensión menor, se enramaron, 
se destacaron algunas palabras por medio de la tipografía (como "palabras-anzuelo que intentan pescar al lector a primera vista"; 2013: 75), en poemas breves se destacó el blanco de la página (7377), los versos se descompusieron en líneas disformes, ondiformes, dislocadas, discontinuas y crestas tipográficas para sugerir la idea de un "oleaje tipográfico" (78).

$\mathrm{Al}$ margen de que las intenciones editoriales se cumplan o no en el proceso de lectura, creo que la intervención editorial tiene otra función no prevista por el equipo de trabajo: esta novedosa tipografía poética puede ser una invitación a leer, pero también una invitación a abandonar el libro cuando la lectura se vuelve muy intrincada. Puede alentar al que lee, pero también alejarlo del mismo contenido de los versos. En el diseño tradicional, cifrado en distinciones tipográficas convencionales pertinentes (el módulo y la disposición espacial, por ejemplo, para distinguir título, epígrafe y texto del poema), la disposición colométrica, los blancos de la página, la distribución uniforme de los poemas, la poda de los callejones, son estrategias puestas ahí para facilitar la lectura a través de distintos modelos cognitivos o esquemas de imagen (patrones dinámicos que proporcionan al que lee una estructura coherente y significativa durante el proceso de lectura; vid., Peña Cervel, 2016) y permitir a quien lee concentrar su esfuerzo atencional en el contenido de los versos, en sus valores acústicos, en las repeticiones significativas (isotopías, isotaxias, anáforas, etc.). En esta intervención editorial, por el contrario, la distribución espacial, la tipografía y el uso del color responden a un acto de fuerte disonancia: están ahí para desautomatizar el acto de leer y complicarlo por medio de distintas estrategias atencionales basadas en la percepción. De hecho, todas ellas han sido tratadas en el manual básico de atención-percepción en español (Munar, Rosselló y Sánchez-Cabaco, 1999): la percepción del contraste (1999: 267-300), la percepción del color (301-337), la organización perceptual y el 
reconocimiento visual del objeto, con especial interés en la oposición entre sistemas lineales y no lineales (339-378), la percepción del tamaño (379-409), etc.

Esta disonancia sistemática con la mise en page convencional afecta, principalmente, los procesos de planeación de la lectura y obliga a quien lee a participar más activamente ante la falta de patrones o esquemas de imagen reconocibles y a involucrarse creativamente con la página para realizar varias operaciones atencionales previas a la decodificación de los contenidos, como: 1) identificar y aislar grupos perceptivos; 2) ordenarlos en una secuencia lineal conforme a estímulos perceptivos diversos y, en la mayoría de los casos, intuitivos, como disposición espacial, tamaño, color, contigüidad, orientación del texto, etcétera; 3) planeación estratégica del recorrido de lectura a partir de la información recabada en los puntos anteriores; 4) identificación de metas cognitivas, y 5) decodificación del texto poético.

Como puede advertirse, las etapas de selección de estímulos procesables y vigilancia del proceso atencional consumen la mayor parte de la energía atencional y dejan un espacio reducido a la decodificación del texto poético. Lo anterior, expuesto con simpleza, significa que la energía atencional invertida en la detección de los recorridos posibles de lectura inhibe la decodificación del texto mismo, reducido a un segundo plano de percepción. En un proyecto de intervención como éste, la lectura es un acto tortuoso que busca lectores conscientes de su actividad, para llenar la página de un sentido arrancado con esfuerzo intelectural (palabra sombrilla procedente de intelectual y lectura), participativo y con una sobrecarga de energía atencional a los estímulos visuales y a los recorridos posibles de lectura. El resultado se vuelve más complejo por la voluntad explícita en cada caso de no ilustrar el poema (Calleja Macedo, 2013: 64), lo que redobla el esfuerzo atencional ante la disociación entre la carga visual del poema y el componente figurativo. 


\section{b) Las Cenizas del Quemado en VersodestierrO}

Quizá la principal desventaja de quien lee frente a la intervención editorial es cierta falta de conciencia, lo que permite a quien edita jugar con planos muy profundos en términos de procesos perceptivos y atencionales. En el caso de la Colección Las Cenizas del Quemado de VersodestierrO, la costumbre de prolongar la cartulina de la contraportada hasta envolver el volumen provoca un intercambio de lugares: la portada ocupa el sitio de la contraportada y la contraportada se desplaza hasta la prolongación envolvente. Abrir un libro de esta colección requiere ya un esfuerzo cognitivo para identificar el sentido correcto de la acción de desplegado. Aquí, la experiencia intuitiva del que lee al abrir un libro convencional debe resistir al sabotaje de la intervención editorial y sobrevivirlo durante el momento de la lectura, porque una vez abierto el libro se convierte en un tríptico donde siempre queda a la vista un pequeño prólogo de una página, mientras la obra corre por las otras dos partes en movimiento. Se trata de preparar a quien lee para una práctica de lectura tortuosa.

La experiencia mejora mucho, sin embargo, al momento de la lectura, porque el tamaño de la página respeta el verso de un tamaño mediano, de modo que pocas veces debe recurrirse al corte de verso. Los poemas en estas ediciones se resignifican $-\mathrm{O}$ no- debido a la presencia, en la portadas y en páginas interiores, de colaboraciones con diversos artistas plásticos. Por lo general, la relación entre imagen y texto sugiere cierta motivación, de modo que la imagen ilustra el poema y viceversa, aunque este vínculo sólo puede establecerse una vez leída la obra poética. En Jauría, de Javier Gaytán, las espátulas de Kenta Torii traducen con eficacia el estilo descarnado y cínicamente doloroso de la poesía del autor, de suerte que muchas de las imágenes acompañan los poemas. Los retratos y primeros planos de la portada y algunos interiores (2009: 
5 y 43) ilustran figurativamente la voz lírica en primera persona, dominante en casi todos los poemas (un caso excepcional del uso de la tercera persona contrasta con el tema expresado en el título: "Pinceladas para un autorretrato"; 2009: 42); dos de las espátulas muestran andróginos con senos muy visibles (2009: 25 y 37), lo que recuerda temas tratados en el primer poema ("canto a un dios homosexual", 2009: 13) y en otros posteriores (como "Me fascinan los senos del travesti...", 2009: 26). En Ronda de muertos, de Tanya de Fonz, la denuncia social también se moviliza en la obra plástica de Eduardo G. de la Cruz, en su mayoría sujetos colectivos anónimos con máscaras que recuerdan algunas escenas de los trípticos del Bosco, pero también miembros amputados (una pierna y un dedo o un ojo enorme con cuatro pares de piernas). Sobresale, como sucede con Gaytán, la ilustración figurativa: el título, por ejemplo, está ilustrado en la portada por una diana giratoria cuyo entorno está formado por 21 brazos con mudras distintos en las manos correspondientes; al centro de la diana está una especie de corazón atravesado por una brizna de pasto (imagen recurrente para indicar el inicio de los primeros cuatro apartados). Este collage figurativo se conecta con la perspectiva impuesta por el segundo poema de la colección, donde la ronda de muertos se compone por partes de cuerpos diversos, lo que expresa una violenta percepción fragmentada del individuo:

El polvo se esparce

incinerante vals

mano blanca encaja en tronco negro

cabeza amarilla, filosofía hindú

tronco blanco encaja con mano negra

cabeza hindú y filosofía amarilla

la mano saluda al tronco

el tronco a la mano

la cabeza a la filosofía 
la filosofía a la cabeza

de manos y manos y troncos y troncos

conformándose los incinerados.

[...]

Ronda de tantos troncos y manos

manos y troncos

el que llegue al último

saluda primero (2005: 10)

Para el libro de Eva Castañeda, Nada se pierde, las tintas zoomórficas (mujeres y hombres con caras de perros o de zorros) de Jorge Santana anticipan la entrada a un universo complejo donde se rescatan, de forma un poco laxa, los nexos figurativos con el poema "Instantáneas zoologías", cuyos subtítulos son "Mujer elefanta”, "Mujer cebra”, "Mujer jirafa” y "Mujer gata” (2012: 55-58).

Desde esta perspectiva, pareciera que hay alguna motivación entre la obra plástica y los textos publicados, pero en la práctica lectora los vínculos sólo se manifiestan cuando el texto que acompañan se ha leído muy cuidadosamente. Antes de la lectura integral, lo único que texto e imagen parecen compartir es una estética repulsiva, donde las imágenes deformes son los primeros indicios perceptuales para iniciar el proceso atencional en varios planos; el más obvio, me parece, es del de la provocación artística, donde el objeto plástico propone una planeación de la lectura basada precisamente en una estética repulsiva, lo que en el fondo se comprueba en la lectura de los textos mismos, pues en ningún caso puede hablarse de una tendencia hacia una belleza poética convencional. Eva Castañeda, por ejemplo, apuesta por imágenes poéticas tomadas del entorno inmediato ("Algunas ideas deberían gastarse como se gastan / los zapatos, las leyes, los monumentos" o "Mi vecina es la mejor cantante de karaoke de la colonia"; 2012: 11); Javier Gaytán recurre a imágenes que provocan un rechazo inmediato ("La vagina de la abuela / se desgrana en los dedos / de mi ado- 
lescencia"; "Mientras los orines de la perra / se confunden con las erupciones de mis labios"; 2009: 16 y 21) igual que Tanya de Fonz (aunque en su poesía hay algo de onírico que suaviza la violencia implícita: "Niños con cabeza en mano saltan /niñas con sangre de vagina juegan. / El niño mete la mano en la sangre, / la sangre grita a carcajadas, / lleva la cabeza del niño"; 2005: 12).

Las imágenes que acompańan los textos rebasan rápida y decididamente el figurativismo superficial y ayudan a quien lee en la planeación de las estrategias más convenientes de lectura; así, la estética repulsiva de la obra plástica ańadida prepara al que lee sobre la naturaleza no menos repulsiva de las imágenes poéticas. Estos estímulos se relacionan directamente con el procesamiento preatencional o no consciente (vid., por ejemplo, Botella $\mathrm{Au}$ sina, 1999: 89-90) y resultan más eficaces que los mismos textos por una buena razón: la percepción del plano plástico es integral, unitaria y simultánea, por lo que una sola mirada a las portadas resulta más efectiva que la lectura completa del volumen página tras página para unir las distintas isotopías y darle forma a un comentario general. Al menos en un primer acercamiento, el plano de la intervención editorial constituye un conjunto de estímulos aparentemente irrelevante (lo que se llama en psicología cognitiva estímulos distractores), pero que puede orientar la interpretación de los estimulos principales o imperativos en el texto sin que el lector o lectora se percate de ello. Por el contrario, quien se acerca a estos libros estará alerta, luego de la percepción preatencional de las colaboraciones plásticas, para identificar todas aquellas isotopías del texto que puedan relacionarse con esa misma estética feísta. En el fondo, la intervención editorial ofrece mecanismos de orientación preatencional de forma intuitiva y, por ello mismo, también con la mayor eficacia.

Estos ejercicios de estilo editorial tienen como propósito volver atractiva una colección en la que los nombres de los autores no 
necesariamente garantizan las ventas; de hecho, si una iniciativa como VersodestierrO subsiste es porque viene acompañada por un sólido proyecto de divulgación a través de presentaciones, talleres o venta al menudeo por las calles (Rémura, 2008: 102-105). Parecería que publicar autores fuera del canon obliga a producir libros que también impacten a otras áreas de percepción de quienes leen, porque en otras editoriales de autores canónicos bien consolidados como Era o Fondo de Cultura Económica no se hace ninguna distinción visible entre los libros de narrativa y los de poesía, y cuando se presentan imágenes, como en el caso excepcional de Álbum Iscariote de Julián Herbert, las mismas proceden del trabajo creativo del autor y están justificadas dentro de su poética (por ejemplo, las series fotográficas de 2013: 39-51 y 131-137).

\section{c) Alejandro Magallanes y Almadía}

Almadía, editorial joven oaxaqueña que muy pronto ha logrado afirmarse como una casa de referencia para la literatura mexicana de las últimas promociones, ha seguido una estrategia editorial parecida a la de VersodestierrO (apartada en lo posible del financiamiento público), aunque en sus filas se encuentran autores con reconocimiento nacional e internacional como Francisco Hernández, Jorge Fernández Granados, Tedi López Mills, Marcelo Uribe, Luigi Amara, Hernán Bravo Varela, Luis Felipe Fabre, etcétera; en ningún caso puede hablarse de autores y autoras desconocidos. Los libros publicados en la colección POESÍA (antes PLEAMAR) coinciden en su intención lúdica gracias a la intervención editorial de Alejandro Magallanes, de quien la misma Almadía ha publicado ¿Con qué rima tima? (2011) y quien quizá alcanza uno de sus mejores momentos como diseńador con la antología de Mario Santiago Papasquiaro, Arte \& basura (2012), con poemas selec- 
cionados por Luis Felipe Fabre (en una colección en formato algo mayor).

Aunque el trabajo de Alejandro Magallanes ofrece resultados muy diferentes en cada caso, creo que el que lee puede advertir fácilmente cierta orientación en la lectura a partir de los estímulos atencionales o preatencionales que agrega con su intervención. En Última función de Marcelo Uribe, uno de los primeros volúmenes de la colección, la portada muestra al centro una puerta de madera rústica construida con tres tablones, una perilla, una cerradura, con un fuerte contraste cromático entre la puerta color marrón y el fondo blanco, bordeada por el típico troquelado de la serie: al abrir dicha puerta, el que lee se encuentra con unas instrucciones para preparar un gallo en origami; en las guardas del libro, las viñetas representan un sillón, una llave y una letra " $r$ ", oscuros sobre fondo blanco, y en las portadas internas se advierte la imagen de una caja para mudanza, cerrada y lista para ser enviada, y una etiqueta adhesiva con los símbolos "proteger de la lluvia", "frágil" y "este lado para arriba". En todos los casos, se trata de estímulos atencionales fácilmente identificables como objetos perceptivos por el alto contraste entre áreas adyacentes (el fondo blanco y las respectivas imágenes; vid., al respecto, Aznar Casanova, 1999: 267).

La tendencia de los sujetos expuestos a estos estímulos atencionales será llegar a una percepción integral, donde la suma de una puerta, un sillón y una llave tiene como resultado una casa fragmentada; por lo tanto, una caja para mudanza y la etiqueta adhesiva permiten deducir que se trata de un cambio de casa. Esta orientación preatencional provoca que el que lee se adentre en la decodificación del texto probablemente se fije con mayor interés en "La casa" (32-38) -donde uno de los temas principales es la frágil existencia de lo que parecía tan sólido como una edificación- y en el poema que cierra la compilación y da título al libro completo, "Última función" (103-105), donde se tematiza el día en que 
se realiza la mudanza y la casa queda sola y cerrada. Si el que lee siguió el orden editorial planteado por Alejandro Magallanes (el recorrido inicia por una puerta que se abre y concluye con la casa que se abandona y se cierra luego del último poema), la misma experiencia de manipulación del volumen, con el troquelado que efectivamente permite abrir la puerta de la casa, convierte a este libro en una pequeña casa física que invita a la exploración y cuyos estímulos preatencionales permiten afianzar un recorrido de lectura a través de esa experiencia táctil volumétrica.

Después de la lectura de este poema, todos los indicios materiales se conectan entre sí y hacen sentido, pero la pregunta debe formularse al revés: ¿no será el indicio material y la interpretación de Alejandro Magallanes por medio de esta intervención editorial lo que dirige nuestro interés hacia "La casa" y "Última función"? De nuevo, la contundencia e inmediatez perceptual de las imágenes orientan al que lee en la preparación de recorridos de lectura válidos. Si el que lee no contara con estos estímulos visuales y táctiles de la intervención de Magallanes, cuyo resultado es una orientación preatencional clara, y sólo se guiara por el puro título del poemario y su homólogo poema final, encontraría elementos para referirse al término de una representación teatral en, al menos, tres isotopías diseminadas a lo largo de las tres secciones en las cuales se divide el libro. En la primera parte del poemario (2008: 13-39), se recurre al mito de Pigmalión para explorar la relación entre los referentes que sirvieron de modelo y sus respectivas representaciones artísticas en la obra de Rothko, Degas o Hopper ("Una ventana para Mark Rothko", "Cielo vacío", "Pétalos", "El ensayo", "Lluvia de oscuridad", etc.), con lo que la representación teatral se incluye en el plano más general de la representación artística; en la segunda parte (45-72), se tematiza la permanencia del recuerdo ante una presencia ausente, en el plano ya no del arte, sino de la memoria (como aclara la voz lírica al inicio de esta sección: "la luz deja para 
siempre / los pinceles, / la paleta, / las espátulas, / el taller”; 45); la tercera parte (77-105), consecuentemente, es una miscelánea de recuerdos personales. Mientras la intervención editorial de Magallanes ofrece una orientación preatencional clara hacia el tema de la casa, en su apertura y cierre, el poemario propone a través de varias isotopías semánticas un trayecto más rico desde la representación en el arte hasta la representación en la memoria, cuya apertura y cierre es una "Última función" como título y poema conclusivo.

En $A$ pie, de Luigi Amara, la portada es un zapato deportivo tipo Converse y el suaje está ubicado en la punta, de modo que al levantarlo aparecen los dedos desnudos de un pie, paradójicamente vistos desde abajo. Igual que en el libro de Marcelo Uribe, el contraste es muy fuerte para pasarlo fácilmente por alto y el tamaño de la imagen prácticamente abarca toda la portada. La representación del pie desnudo en otro ángulo se reproduce en las guardas, en la portada interior se presenta un grabado que da la impresión de ser antiguo del sistema muscular del pie y sobre el colofón se presenta, por último, el esqueleto de un pie. La historia visual contada por Alejandro Magallanes empieza con un zapato tenis, sigue con un pie desnudo y una exposición quirúrgica interna de un pie, hasta concluir en los puros huesos, como si el pie se hubiera gastado al caminar. Los estímulos preatencionales insinúan en este ciclo iconográfico una secuencia de desgaste físico del pie en un trayecto errabundo (tema central del poemario).

Quizá lo más sugerente de la intervención editorial no esté en los preliminares, sino en las fotografías y viñetas que dividen un poema largo en varios poemas de extensión dispar (decisión editorial discutible de por sí): se trata de huellas o pequeñas fotografías alusivas a lo que se tematiza en los poemas (unos conos de helado cuando se refiere a Arcos de Belén; varios pares de piernas cruzando Eje Central cuando se refiere esta avenida; un mapa cuando Amara escribe "un mapa / siempre está por dibujarse"; el cartel del 
Cine Venus cuando se habla del mismo, y otros). El trabajo ilustra los contenidos del poema, aunque las referencias de la intervención editorial siempre son oblicuas. Con ello, la energía atencional de quien lee se orienta página a página hacia las constantes denotaciones urbanas, lo que inhibe, por supuesto, el plano intimista del poema (o, al menos, lo coloca en un segundo plano). En este caso, la atención objetiva al texto tiene que contender continuamente con el conjunto de estímulos distractores (vid. Tejero Gimeno, 1999: 37) sembrados por la intervención editorial y deja a un lado información que sugiere una naturaleza fuertemente intimista en este paisaje urbano: "La ciudad es provisional. / Un recorrido entre los recuerdos / y las ausencias. / Entre / las calles de la mente y el azar / de los acontecimientos. / Encrucijadas. / La ciudad es el trazo invisible / que uno deja" (2010: 63). La ciudad es en realidad un pretexto para hablar de un trayecto intimista, pero la intervención editorial la destaca por medio de varios close-up y le confiere un protagonismo que modifica la intención original.

En Poemas de terror y de misterio, homenaje de Luis Felipe Fabre al cine serie $\mathrm{B}$ y aguda sátira sobre el tratamiento de la violencia dentro de algunos corpúsculos de creadores oportunistas, la intervención editorial ofrece desde la portada (con la ilustración de una mujer hilarantemente asustada, del tipo de las perfectas amas de casa que aparecían en la publicidad de los ańos cincuenta), las guardas (con siluetas de personajes emblemáticos del cine de terror de películas serie B) y viñetas con mascarones de monstruos que separan las diferentes secciones del libro (Drácula, la novia de Frankenstein, el hombre lobo, un extraterrestre y, al final, hasta una sor Juana bizca); por lo tanto, el que lee puede intuir que se le invita al disfrute de una experiencia lúdica. Cuando este mismo lector abre el suaje o troquelado de la portada, verá transformarse a esa señora ama de casa en un amenazante híbrido de cuyo torso se desprenden los tentáculos de un pulpo, lo que nos conduce a 
reflexionar sobre la ambigüedad de ser quienes padecemos el miedo y, simultáneamente, quienes lo provocamos... o simplemente mueve a risa por lo inesperado del contenido del suaje.

La orientación atencional que determinan estos elementos lúdicos inhibe, de nuevo, la lectura seria de los poemas. En el "Trailer 1 ”, por ejemplo, la misteriosa desaparición de varias chicas y la indiferencia policíaca sugiere una primera incursión en la poesía comprometida, con lo que podría ser una crónica mínima sobre los feminicidios de los últimos años, condenables por sí mismos, pero también por la ineficacia con que han sido tratados y no resueltos por las autoridades locales, en Ciudad Juárez o en el Estado de México, y por los medios de comunicación, que encubrieron (o ignoraron, en el mejor de los casos) la situación durante tantos años. Esta primera expectativa se ve frustrada cuando las chicas desaparecidas regresan como mujeres vampiro, sedientas de venganza y en su forma más bella, como actrices de una película serie B ("Las chicas han vuelto: Una película de Luis Felipe Fabre. // Las chicas han vuelto: próximamente en cines"), transformadas por esa extrańa capacidad que tiene el arte para cambiar cualquier realidad, incluso la más fea y repugnante, en algo bello, trascendente y aséptico. Cuando ingresa a las desaparecidas al terreno de la estética literaria las ha convertido en mujeres inmortales, en mujeres vampiro que trascenderán la vida humana mientras la cultura exista. El poema plantea una paradoja muy seria: el arte tiene la capacidad para sublimar la realidad, pero esta sublimación por sí misma no devuelve la vida a las mujeres que sufrieron una muerte violenta. En los poemas siguientes, Luis Felipe Fabre explora desde varias perspectivas si el arte de las elites cumple de verdad con su responsabilidad como una herramienta de concienciación social. El desenfado humorístico de la presentación editorial, sin duda, prepara al que lee para encontrar en el ridículo el principal fin de Fabre, pero en el fondo este ridículo se propone enfrentarnos a una 
realidad muy diferente desde un giro irónico que acompaña a todo el poemario: las armas con las que cuenta el arte para provocar la denuncia no son efectivas. El humor de la propuesta es aparente (y editorial, claro), porque en el fondo de los textos subyace una crítica muy seria al impacto social que puede tener el arte comprometido en nuestros días, cuando la sociedad parece tan alejada de las manifestaciones artísticas.

\section{¿Conclusiones?}

Estos son algunos ejemplos que pueden alentar una lectura más atenta de la intervención editorial y de un soporte material que debería, al menos en parte, preocuparnos como lectores y lectoras, porque podría estar orientando nuestra lectura al atravesar nuestra coraza más débil: la lectura asociativa de los planos materiales y una fuerte orientación preatencional que se nos presentan mucho antes que los propios contenidos poéticos. Se trata, en el fondo, también de estar más atentos a las intenciones comunicativas de quien edita y de leer con menos prejuicios y más atención al texto.

\section{Bibliografía}

Amara, Luigi, 2010, A pie, Almadía, México.

Aznar Casanova, José Antonio, 1999, "Percepción del contraste: procesamiento de bajo nivel”, en Atención y percepción, Enric Munar et al., Alianza, Madrid, pp. 267-300.

Botella Ausina, Juan, 1999, "Estudio experimental de la atención”, en Atención y percepción, Enric Munar et al., Alianza, Madrid, pp. 63-98. 
Calleja Macedo, Efrén, 2013, Nos sobran los motivos, Crónica editorial de No todas las islas, Idónea comunicación de resultados (Tesis de Maestría), Universidad Autónoma Metroopolitana Xochimilco, México.

Castañeda, Eva, 2012, Nada se pierde, VersodestierrO, México.

Cheadle, Samuel W. y Semir Zeki, 2014, "The Role of Parietal Cortex in the Formation of Color and Motion Based Concepts", Frontiers in Human Neuroscience, núm. 8, art. 535, disponible en: <doi: 10.3389/fnhum.2014.00535> (consultado: 22/V/2016).

Cifuentes Férez, Paula, 2016, "La semántica conceptual”, en Lingüistica cognitiva, Iraide Ibarretxe-Antuñano y Javier Valenzuela (dirs.), Anthropos, Barcelona, pp. 189-211.

Collins, Zazil Alaíde, 2012, No todas las islas, Gobierno del Estado de Baja California Sur / Instituto Sudcaliforniano de Cultura / Conaculta, México.

Cortés, Jair, 2013, "Zazil Collins, México, 1984, No todas las islas", La Otra, Revista de Poesía + Artes Visuales + Otras Letras, disponible en: http://www.laotrarevista.com/2013/03/zazil-collinsmexico-1984-no-todas-las-islas/> (consultado: 1/II/2015).

Fabre, Luis Felipe, 2013, Poemas de terror y de misterio, Almadía, México.

Flores, Malva, 2014, La culpa es por cantar. Apuntes sobre poesia y poetas de hoy, Literal Publishing / Conaculta, México.

Fonz, Tania de, 2005, Ronda de muertos, imagen al tacto de G. de la Cruz, VersodestierrO, México.

Freeman, Margaret H., 2012, "Blending and Beyond: Form and Feeling in Poetic Iconicity", en Cognitive Literary Studies, Current Themes and New Directions, Isabel Jaén y Julien Jacques Simon (eds.), University of Texas Press, Texas, pp. 127-143. 
Gaytán, Javier, 2009, Jauría, espátulas de Kenta Torii, VersodestierrO, México.

Hadatty Mora, Yanna, 2014, "200 jueves. La novela semanal de El Universal Ilustrado", ponencia presentada en el 3er Coloquio Internacional la Novela Corta en México, 10 al 13 de noviembre de 2014, en Gustavo Jiménez Aguirre (dir.), La Novela Corta, una Biblioteca Virtual (en línea), UNAM / Conaculta/Fundación para las Letras Mexicanas, disponible en: <http://www.lanovelacorta.com/> (consultado: 7 /II/2015).

Herbert, Julián, 2013, Álbum Iscariote, Era / Conaculta, México.

Ibarretxe-Antuñano, Iraide y Javier Valenzuela (dirs.), 2016, Lingüistica cognitiva, Anthropos, Barcelona.

Ishizu, Tomohiro y Semir Zeki, 2014, "Varieties of Perceptual Instability and their Neural Correlates", NeuroImage, núm. 91, pp. 203-209.

Jaén, Isabel y Julien Jacques Simon (eds.), 2012, Cognitive Literary Studies, Current Themes and New Directions, University of Texas Press, Texas.

Ljungberg, Christina, 2012, Creative Dynamics, Diagrammatic Strategies in Narrative, John Benjamins Publishing, Amsterdam/Philadelphia.

, 2009, "Subjectivity as Performance in Literary Texts", en Redefining Literary Semiotics, Harri Veivo, Christina Ljungberg y Jorgen Dines Johansen (eds.), Cambridge Scholars Publishing, Newcastle upon Tyne, Reino Unido, pp. 86-108.

, 2007, "Triangular Strategies: Cross-Mapping the Curious Spaces of Siri Hustvedt, Paul Auster and Sophie Calle", en Mapping Liminalities, Thresholds in Cultural and Literary Texts, Lucy Kay, Zoë Kinsley, Terry Phillips y Alan Roughley (eds.), Peter Lang, Bern, pp. 111-135. 
Magallanes, Alejandro, 2011, ¿Con qué rima tima?, Almadía, México.

Munar, Enric, Jaume Rosselló y Antonio Sánchez-Cabaco (coords.), 1999, Atención y percepción, Alianza, Madrid.

Papasquiaro, Mario Santiago, 2012, Arte \& basura, una antología poética de Mario Santiago Papasquiaro, Luis Felipe Fabre (sel., y pról.), Almadía, México.

Paz, Octavio y Arnaldo Orfila, 2005, Cartas cruzadas, Siglo XXI, México.

Peña Cervel, María Sandra, 2016, “Los esquemas de imagen”, en Lingüistica cognitiva, Iraide Ibarretxe-Antuñano y Javier Valenzuela (dirs.), Anthropos, Barcelona, pp. 69-96.

Pizarro, Jerónimo, 2012, La mediación editorial. Sobre la vida póstuma de lo escrito, Iberoamericana/Vervuert, Madrid /Frankfurt am Main.

Prada, Juan Martín, 2001, La apropiación posmoderna. Arte, práctica apropiacionista y teoría de la posmodernidad, Fundamentos, Madrid.

Rémura, Adriano, 2008, "Autonomía o del por qué hacer un proyecto civil”, Tirofijo Revista Cultural del Bajio, núm. 00, año 1, pp. $97-105$.

Segura, Jesús y Toni Simó, 2012, Arte contextual. Intervenciones en el espacio público, Visión Libros, Madrid.

Shaeffer, Jean-Marie, 2013, Pequeña ecología de los estudios literarios, ¿por qué y cómo estudiar la literatura, Laura Fólica (trad.), FCE, México.

Shigihara, Yoshihito y Semir Zeki, 2013, "Parallelism in the Brain's Visual Form System", European Journal of Neuroscience, núm. 1-9, disponible en: <doi:10.1111/ejn.12371> (consultado: 16/ V2016). 
Stockwell, Peter, 2002, Cognitive Poetics. An Introduction, Routledge, Londres / Nueva York.

Tejero Gimeno, Pilar, 1999, "Panorama histórico-conceptual del estudio de la atención”, en Atención y percepción, Enric Munar et al., Alianza, Madrid, pp. 33-62.

Torres de la Rosa, Danaé, 2015, Avatares editoriales de un género: tres décadas de la novela de la Revolución mexicana, Bonilla Artigas Editores / Instituto Tecnológico Autónomo de México, México.

Tsur, Reuven, 2008, Toward a Theory of Cognitive Poetics, Sussex Academic Press, Brighton / Portland, Oregon.

, 2003, On the Shore of Nothingness: Space, Rhythm, and Semantic Structure in Religious Poetry and its Mystic -Secular Counterpart- A Study in Cognitive Poetics, Imprint Academic, Exeter.

Uribe, Marcelo, 2009, Última función, Almadía, México.

Volpi, Jorge, 2011, Leer la mente, Alfaguara, México.

Zeki, Semir, 2015, "Area V5 - A Microcosmo of the Visual Brain", Frontiers in Integrative Neuroscience, núm. 9, art. 21, pp. 1-18, disponible en: <doi: 10.3389/fnint.2015.00021> (consultado: 29/V/2016).

, 2015a, "A Massively Asynchronous, Parallel Brain", Philosophical Transactions The Royal Society, núm. 370, pp. 1-14, disponible en: <http://dx.doi.org/10.1098/rstb.2014.0174> (consultado: 28/V/2016).

, 2009, Splendors and Miseries of the Brain: Love, Creativity and the Quest for Human Happiness, Wiley-Blackwell, West Sussex, Reino Unido. 
Zeki, Semir y John Paul Romaya, 2010, “The Brain Reaction to Viewing Faces of Opposite -and Same- Sex Romantic Partners", PLoS ONE, núm. 5, art. 12, pp. 1-8, disponible en: <e15802. doi:10.1371/ journal.pone.0015802> (consultado: 28/V/2016).

Zeki, Semir y Jonathan Stutters, 2013, "Functional Specialization and Generalization for Grouping of Stimuli Based on Colour and Motion", NeuroImage, núm. 73, pp. 156-166.

Recibido: 07 de septiembre de 2015 Aceptado: 16 de mayo de 2016 